\title{
The Criticism of Consumption Alienation by William Leiss
}

\author{
Xiaying LV \\ School of Marxism, Zhejiang University, Hangzhou city, Zhejiang Province, China \\ 775987695@qq.com
}

\begin{abstract}
Keywords: Consumption Alienation William Leiss "Dual needs"
\end{abstract}
\begin{abstract}
Leiss believes that the main expression of the alienation of capitalist society has shifted from labor alienation to consumption alienation, and the fuse of the future social revolution will also occur in the consumption field rather than in the production field. In the study of the alienation of consumption, he carried on the expansion of ecological criticism on the basis of Marcuse's theory of criticizing consumer alienation, especially the capitalist society considering only itself and the nature as the object of use and control, only focus on its own needs to advocate wantonly consumption without regard to the ecological environment of human center. Leiss's understanding of the alienation of consumption is a high consumption behavior based on the "dual needs", under the concept of control nature. The essence of consumer alienation is the dual control of people and nature by the ruling class and Leiss believes that the future social development direction of the harmonious coexistence of man and nature should be the "conserver society".
\end{abstract}

\section{Introduction}

William Leiss (1939 - ), one of the main representatives of ecological Marxism, Canadian modern left-wing scholar, division from Marcuse, is committed to integrating ecology with Marxism. Leiss believes that the main expression of the alienation of capitalist society has shifted from labor alienation to consumption alienation, and the fuse of the future social revolution will also occur in the consumption field rather than in the production field. In the study of the alienation of consumption, he carried on the expansion of ecological criticism on the basis of Marcuse's theory of criticizing consumer alienation, especially the capitalist society considering only itself and the nature as the object of use and control, only focus on its own needs to advocate wantonly consumption without regard to the ecological environment of human center. Leiss's understanding of the alienation of consumption is a high consumption behavior based on the "dual needs", under the concept of control nature.

\section{Consumption Alienation under "Dual needs" and Its Ecological Consequence}

The analysis of consumption is inseparable from the analysis of the needs of people, because it is the need promote people to consume. The concept of "false needs" proposed by Herbert Marcuse of the Frankfurt school is the classification of needs from the source of needs, that is, the needs of human' instinct is "real needs", and the needs to impose it from the outside is "false needs". Leiss translated Marcuse’s expression of "real needs" and "false needs" into "needs" and "desires". In Leiss’s context, "needs" is the "real needs", and "desires" is the "false needs" of people. "The needs of one person are the minimum requirements for the maintenance of physical and mental health, shared by him with the rest of the culture in which he is located "[1], which is objective and real, but the desire of a person is subjective and false infused by the external society. On the basis of Marcuse's analysis of "false needs", Leiss further analyze the composition of needs and the consequences of its influence on the ecological environment. If Marcuse focuses on the analysis of the extension of needs and the classification of needs, then Leiss focus on the analysis of the connotation of needs. 
Leiss believes that needs have double attributes, that is, "each expression or presentation required is accompanied by a material association and a symbolic or cultural connection."[1] In other words, Leiss believes that the needs are a unity of material needs and cultural needs, and there are no pure material needs or cultural needs. Material needs and cultural needs are not two separate existences. For example, the need for food seems to be human material needs, but how to obtain food, what food to obtain, and how to make food is closely related to the cultural development of human beings. Human behavior is always based on the specific combination of material needs and cultural needs. Based on the understanding of the dual attributes of needs, Leiss's understanding of commodity is also dual, namely, the goods regarded as "material - symbol entity"[1]. This means that the commodity is the unity of material and symbol, that people purchase goods not only for the sake of use value, but also for the symbolic value.

It is worth noting that material needs and cultural needs are different in their roles on promoting human needs. Human' material needs are limited, while cultural needs' are infinite. According to Maslow's hierarchy of needs theory, people always meet their material needs first, and then meet the cultural needs. Maslow's theory of needs are divided into five levels, namely, physiological needs, security needs, social needs, respect needs and self-realization needs. A higher level of need will not appear until the needs of the previous level have been achieved. But Leiss believes that material and spiritual aspects needs cannot be separated from the level of a stage, on the contrary, the needs of material "will continue extend even to the 'psychological' field"[2]. Maslow's hierarchy of needs theory assumes that the human's material needs have a satisfaction point, and when the meeting point is reached, the human will pursue a higher level of needs. The satisfaction of the material needs of the human being will always come before the satisfaction of the human's cultural needs. Maslow holds the diachronic development perspective to analyze needs. But according to Leiss, in the so-called physiological needs of Maslow's lowest level, the needs are also the combination of material needs and cultural needs. And after the material needs of human beings are basically met, the cultural needs of people will become the dominant needs. It is worth noticing that the cultural needs of people are often have no limits.

The endless cultural needs of human beings must have the corresponding material carrier as its supporter. This means that under the impetus of the endless cultural needs, it is impossible to ignore the material carrier behind the consumption of symbols, as Baudrillard thinks. Baudrillard's analysis of consumption only pays attention to the symbolic social significance level and develops the semiotic criticism of consumption alienation, but ignores the material attributes needed. Leiss is aware that under the guidance of consumption, whether based on the limited material needs or on the unlimited cultural needs, they all ultimately call for the material carrier. So any kind of consumption will consume a certain amount of natural resources. Consumption will inevitably cause continuous looting and pressure on the natural ecological environment. In addition, in the modern capitalist society, all needs are guided to the endless consumption. Not only the material needs are to be realized through the purchase of goods, even the needs of self-esteem and selfrealization are to be realized through the purchase and consumption of goods. Thus, the ecological environment always acts as the passive role of providing material materials, and the relationship between human and nature is always in the binary opposition between the subject and object. In a word, Baudrillard promoted the social criticism dimension of consumption alienation, and Leiss promoted the ecological critical dimension of consumption alienation. It is sad to note that the use of resources by capitalist countries is striking. The total population of the capitalist developed countries accounts for a third of the total population of the earth, but it uses $90 \%$ of the total resources of the earth. It is the large consumption of capitalist countries that causes the emergence of the global ecological crisis. 


\section{The Essence of Consumer Alienation is the Dual Control of People and Nature by the Ruling Class}

Leiss thinks that the reason why human beings snatch resources from nature to meet their "dual needs" lies in the ideology of control of the natural. Nature is naturally regarded as the object to meet the needs of human beings. Since nature is the passive object controlled by human beings, it is natural to consume nature to meet the "dual needs" of human beings. The reason why human beings can satisfy their own material and cultural needs by consuming the natural resources rooted in the thought of domination of nature. Under the guidance of the domination of natural, natural resources are regarded as the "non-subjectivity", and are destined to be controlled by human beings. Nature is for the needs of human beings. The root of ecological crisis lies in the ideology of human's control of nature.

Meanwhile, by controlling nature and directing the "dual needs" of human beings to the need for material consumption, the bourgeoisie has successfully controlled people. The control of nature is only a means of controlling people. Through the provision of adequate consumer goods got from nature, the Bourgeoisie can control human beings. But in the pre-modern society, based on the limited control of nature, the ruling class and the ruled class are both greatly restricted by the restriction of natural forces. Thus, the limited satisfaction of the human consumption needs "hampered the emperor or at least to make the authority internal and external very unstable"[3], when the ruling class cannot fully meet the needs of the people by conquering nature but can only rely mainly on the violent rule. With the development of productivity, especially the development of science and technology and the arrival of the capitalist industrial society, the control of the nature by capitalist society got unprecedented promotion. Thus, the capitalist can meet the needs of the public through the control of nature and provide relatively adequate consumer goods for the masses, so the control of people is more and more manifested by the means of meeting the consumption needs of people. This kind of control is nonviolent means of control. The richer the social wealth, the more diverse the choice of human consumption, the stronger the social control is. "The more active the pursuit of control of nature, the more passive the individual will receive; The more powerful the ability to control nature, the weaker the individual power is compared to the overwhelming social reality."[3] The more people see consumption as a means to meet all the needs, and the more consumption, the more control it is.

\section{Way to Overcoming Consumption Alienation}

One of the most serious problems facing the planet is the inappropriate consumption, resulting in environmental degradation and increased poverty. Only by overcoming consumption alienation, making people really play their creativity and initiative in labor, and getting rid of the dependence on consumption, can create conditions for the realization of human liberation and the liberation of nature. It is impossible for human beings to seek unlimited access to nature to meet the alienation of consumption, because nature's resources and carrying capacity are limited, and "no technology can ensure unlimited growth of the economy in a limited biosphere "[4].

To solve the problem of consumption alienation, to solve the waste of the earth resources and ecological environment crisis, we need to "contact the needs of other organisms in the biosphere to understand the needs of human beings"[1]; In fact, we should consider the nature and human beings as a whole. Human consumption can never leave the natural world. Leiss also pointed out that not only human beings have needs and human beings cannot limit themselves to their own needs, but should take nature's needs into account, at the same time use nature's needs to adjust our needs. We need to take into account both the human needs and the needs of the environment.

To cope with the adverse effects of consumption, it is necessary to establish a new theory of needs, to break the absolute correlation between the needs and the material consumption, and to find a civilized society in harmony with nature. Leiss believes that the future social development direction of the harmonious coexistence of man and nature should be the "conserver society". This 
society does not pursue the rapid development of economy. Its "goal is to reduce the commodity as an important factor to meet the needs of human factors, to minimize the need for energy and material to the minimum."[2] People will meet their own needs in the production process. In the consumption field, people will also no longer pursue the quantity of consumption, but pay attention to the quality of consumption.

Commodity consumption is no longer the only way to meet people's needs, the needs of people can be met with diversification. People can meet their satisfaction more than just consumption. They can meet their satisfaction through labor, singing, sports, learning and many more. People shouldn't meet their needs solely on the consumption of goods. As long as person's needs could be met on their own ability rather than relying narrowly on commodities, the means to meet the needs of mankind can be diversified.[2] Thus, the human happiness is not purely rely on consumption, but be more reflected in the acceptance of their own, harmonious interpersonal communication, free labor and the harmony between human and nature. In short, the satisfaction of human beings should come from the production of their own ability, rather than confined to the single consumption activities in the capitalist society.

The pursuit of satisfaction and happiness can be led to the non-consumption field, like in the field of production activities, so that the environmental destruction caused by consumption can be alleviated. This doesn't mean to limit all human consumption activities, but mean that not all the human material and spiritual needs should be pressed on consumption. "There is no inherent evil in the exchange of goods and markets, and there is no reason to think that they should be eradicated. Only when the commodity exchange tends to be the only way to meet the needs, people have reasons to worry."[1] Schumacher also pointed out that "the human needs are endless, and the infinite needs can only be realized in the spiritual kingdom, but not to be realized in the material kingdom".[5] The pursuit of material goods is always limited, and the expansion of the spiritual world is unlimited.

\section{References}

[1] William Leiss. The Limits to Satisfaction [M]. the Commercial Press. Translated by Li Yongxue, 2016697284117124.

[2] William Leiss. The limits to Satisfaction [M]. Kingston and Montreal. McGill - Queen's University Press, 198857112107.

[3] William Leiss: The Control of Nature [M]. Chongqing Press. Translated by Yue Changling, 2007139138.

[4] John Bellamy Foster: Ecological crisis and Capitalism [M]. Translated by Geng Jianxin, Shanghai Translating Press, 200674.

[5] Schumacher: Little is Good [M]. Beijing: the Commercial Press, Translated by Yu Hongjun, 198420. 